\title{
Perceived Responsibility to Initiate Family Health History Discussions among College Women Associated with Individuals Diagnosed with Heart Disease
}

\section{Justin B. Dickerson ${ }^{1 *}$, Matthew Lee Smith², Erica Sosa ${ }^{3}$, E. Lisako J. McKyer ${ }^{4}$ and Marcia G. Ory²}

${ }^{1}$ Department of Health Policy \& Management, School of Rural Public Health, Texas A\&M Health Science Center, USA ${ }^{2}$ Department of Social \& Behavioral Health, School of Rural Public Health, Texas A\&M Health Science Center, USA

${ }^{3}$ Department of Health \& Kinesiology, University of Texas at San Antonio, USA

${ }^{4}$ Department of Health \& Kinesiology, Texas A\&M University, USA

\begin{abstract}
Objectives: To examine young women's perceived responsibility for initiating family health history discussion with their primary care providers when associated with individuals with heart disease.

Methods: Data were obtained from an internet-based survey administered to 232 young women enrolled at a large university. Exploratory factor analysis and structural equation modeling were used to relate these women's health beliefs to their perceived responsibility for initiating family health history discussion with their physicians.

Results: Heart disease self-risk factors were positively related $(\beta=0.21, p=0.005)$ to the physician being responsible for initiating family health history discussion. Motivation from friends and acquaintances to obtain family health history was positively related $(\beta=-0.17, p=0.022)$ to the woman being responsible for initiating family health history discussion.
\end{abstract}

Conclusion: Friends and social networks play an important role in how young women perceive their responsibility for initiating family health history discussion with their primary care providers.

Keywords: Heart disease; Patient-physician interaction; Family health history; Social networking

\section{Introduction}

Heart disease is the leading cause of death in the United States, with total costs of the disease in excess of $\$ 300$ billion annually [1]. Although it is the leading cause of death among American women [2] and in 2006 killed $15 \%$ more women than all types of cancer combined $[2,3]$ cancer continues to be perceived by women as a more common cause of death than heart disease [4]. This incongruence between beliefs and mortality statistics is most pronounced among younger women [4]. Although age-adjusted rates of coronary heart disease mortality in the United States have fallen significantly in the past few decades, annual percentage changes in mortality among younger women are actually increasing [5].

Several studies $[6,7]$ illustrate the importance of family history in the development of coronary heart disease; however, younger women often exhibit less knowledge and awareness of cardiovascular disease risk factors in general compared to men of the same age [8]. Evidence suggests that younger women with a family history of premature myocardial infarction have lower awareness of cardiovascular risk factors and worse lifestyle choices compared to similarly aged men [9].

The role of patient-physician discussions about family history of coronary heart disease has been deemed critical given the incidence rate among women [10]. The purpose of our study is to examine the factors that influence who American college women perceive is responsible (i.e., patient or physician) for initiating family health history discussions. Our study is unique because it examines factors that motivate younger women to take responsibility for family health history discussions with their physicians, or alternatively, why they relegate such responsibility for these discussions to their physicians. The implications of our study for clinical practice improvement are substantial.

\section{Methods}

The "Finding Roots: Exploring Your Family History" study [11] investigated college students' knowledge, perceptions and behaviors with regards to obtaining their family health history, including history of chronic diseases (i.e., cancer, heart disease, diabetes, obesity, HIV/ AIDS and cystic fibrosis). Mixed methodology was utilized to integrate qualitative and quantitative components for instrument development. The survey instrument consisted of 60 items; included Likert-type scales, checklists and close-ended response formats; was disseminated using electronic mail-based recruitment; and took participants approximately fifteen minutes to complete. A total of 703 students voluntarily responded to the Internet-based survey, with the option to discontinue their participation at any time. This study was approved by the Texas A\&M University Institutional Review Board. Sixty percent (n $=422$ ) of survey respondents were women.

Our study focused on female respondents without heart disease who reported associations to individuals diagnosed with heart disease. Types of individuals with heart disease who were associated with the respondent included: a parent, grandparent, sibling, aunt, uncle, cousin, friend, friend's family member, classmate, or co-worker. This

*Corresponding author: Justin B. Dickerson, Health Services Research, Department of Health Policy \& Management, School of Rural Public Health, Texas A\&M Health Science Center, 1266 TAMU, College Station, Texas 77843, USA, Tel: 979-574-2991; Fax: 979-458-4264; E-mail: dickerson@srph.tamhsc.edu

Received November 15, 2011; Accepted January 21, 2012; Published January 23, 2012

Citation: Dickerson JB, Smith ML, Sosa E, McKyer ELJ, Ory MG (2012) Perceived Responsibility to Initiate Family Health History Discussions among College Women Associated with Individuals Diagnosed with Heart Disease: Primary Health Care 2:109. doi:10.4172/2167-1079.1000109

Copyright: (c) 2012 Dickerson JB, et al. This is an open-access article distributed under the terms of the Creative Commons Attribution License, which permits unrestricted use, distribution, and reproduction in any medium, provided the original author and source are credited. 
selection criterion was used to include women who most likely knew about heart disease. This resulted in a sample of 232 college women with an association to individuals with heart disease.

The dependent variable selected for analysis was one item that asked participants to identify whose responsibility it was to initiate family health history discussions in the patient- physician relationship (i.e., the college student or the physician). The 1-10 scale represented a spectrum of perceived responsibility from complete college student responsibility (i.e., a score of 1) to complete physician responsibility (i.e., a score of 10). The dependent variable was normally distributed.

Based on our literature review, we identified 36 observed variables in our instrument most applicable to our research question. Exploratory factor analysis was used to identify common factors among these variables. Principal Axis Factoring was used for variable extraction and Varimax with Kaiser Normalization was used as the rotation method [12]. Missing data was very limited in the sample (i.e., less than 1\%). Kaiser-Myer-Olkin and Bartlett's sphericity tests were used to see whether the data met established criteria to perform factor analysis [13]. Based on prior analysis [14], an Eigenvalue of at least 1 was used to extract variables and a coefficient of at least .40 was used to load a variable on a factor [13]. Variables loading on more than one factor were excluded. Cronbach's alpha was used to test the internal reliability of scales. A coefficient of .70 was set for this purpose $[15,16]$. Analyses were performed with IBM SPSS Statistics version $18[17,18]$ The exploratory factor analysis resulted in six unique heart disease and family health history factors (Table 1).

The factors were analyzed within a structural equation model using IBM AMOS version 18 [17]. The factors served as independent variables in the model, while the perceived patient or physician responsibility to initiate family health history discussions served as the dependent variable. Prior research indicates such a sample of our size (i.e., $\mathrm{n}=$ 232) can produce statistically significant results in a structural equation model context [19].

The modeling process started with an evaluation of all six factors, in addition to the following independent variables: age, sex, ethnicity, education level of parents, whether the respondent had a regular family physician and the type of person diagnosed with heart disease associated with the respondent. Maximum likelihood estimation was used to calculate model estimates. Model paths were considered significant at the $\alpha=0.05$ level. As iterations of the model were considered, insignificant factors and variables were removed, resulting in a final model for analysis.

Several fit metrics were used to determine the final structural equation model. CMIN/df (i.e., chi-square statistic divided by the

\begin{tabular}{|c|c|c|c|c|c|}
\hline Construct & Observed Variables & Factor Coefficients & $\begin{array}{l}\text { Cronbach's } \\
\text { Alpha }\end{array}$ & Score Range & Analytic Sample \\
\hline Heart Disease Self-Risk Factors & $\begin{array}{l}\text { I would most likely develop heart disease due to: } \\
\text { Behavioral causes } \\
\text { Genetic Causes } \\
\text { Environmental Causes }\end{array}$ & $\begin{array}{l}0.89 \\
0.85 \\
0.59\end{array}$ & 0.749 & $0-30$ & $21.41( \pm 5.82)$ \\
\hline $\begin{array}{l}\text { Heart Disease Severity - Physical } \\
\text { Vitality }\end{array}$ & $\begin{array}{l}\text { Heart disease would be detrimental to my: } \\
\text { My quality of life is impacted } \\
\text { My physical well-being is impacted } \\
\text { My sexual encounters are impacted }\end{array}$ & $\begin{array}{l}0.89 \\
0.85 \\
0.74\end{array}$ & 0.730 & $0-30$ & $16.36( \pm 3.13)$ \\
\hline $\begin{array}{l}\text { Heart Disease Severity - Mental } \\
\text { Vitality }\end{array}$ & $\begin{array}{l}\text { Heart disease would be detrimental to my: } \\
\text { My mental well-being is impacted } \\
\text { My social life is impacted } \\
\text { My emotional well-being is impacted } \\
\text { My spiritual well-being is impacted } \\
\text { My academic performance is impacted }\end{array}$ & $\begin{array}{l}0.83 \\
0.83 \\
0.90 \\
0.78 \\
0.81\end{array}$ & 0.878 & $0-30$ & $24.86( \pm 6.50)$ \\
\hline $\begin{array}{l}\text { Cues to Obtain Family Health } \\
\text { History - Immediate Family }\end{array}$ & $\begin{array}{l}\text { I would be motivated to obtain my family health history } \\
\text { if: } \\
\text { I'm diagnosed } \\
\text { I develop symptoms } \\
\text { My sibling is diagnosed } \\
\text { My biological parent is diagnosed }\end{array}$ & $\begin{array}{l}0.85 \\
0.85 \\
0.78 \\
0.74\end{array}$ & 0.804 & $0-4$ & $3.67( \pm 0.87)$ \\
\hline $\begin{array}{l}\text { Cues to Obtain Family Health } \\
\text { History - Friends/Acquaintances }\end{array}$ & $\begin{array}{l}\text { I would be motivated to obtain my family health history } \\
\text { if: } \\
\text { A friend is diagnosed } \\
\text { A friend's family member is diagnosed } \\
\text { Someone I know has symptoms }\end{array}$ & $\begin{array}{l}0.87 \\
0.82 \\
0.81\end{array}$ & 0.786 & $0-3$ & $1.80( \pm 1.22)$ \\
\hline $\begin{array}{l}\text { Cues to Obtain Family Health } \\
\text { History - Education }\end{array}$ & $\begin{array}{l}\text { I would be motivated to obtain my family health history } \\
\text { if: } \\
\text { Learned about genetic risk factors - Non-educational } \\
\text { source } \\
\text { Learned about health condition risk factors - Non- } \\
\text { educational source } \\
\text { Learned about genetic risk factors - Educational } \\
\text { source } \\
\text { Learned about health condition risk factors - } \\
\text { Educational source } \\
\text { A friend tells me family health history is important } \\
\text { A family member says family health history is } \\
\text { important }\end{array}$ & $\begin{array}{l}0.85 \\
0.80 \\
0.78 \\
0.75 \\
0.73 \\
0.70\end{array}$ & 0.859 & $0-6$ & $3.34( \pm 2.23)$ \\
\hline
\end{tabular}

Table 1: Heart Disease and Family Health History Constructs. 
model degrees of freedom) was used to measure the fit of the model to the data. Acceptable values are considered to be as close to 1 as possible [20]. TLI (i.e., Tucker-Lewis index) values approaching 1; and CFI (i.e., confirmatory fit index) values of greater than 0.95 were utilized to test the model to baseline comparisons based on established guidelines [20-24]. TLI reduces model fit as insignificant parameters are added to the model. CFI plays a similar role by evaluating the correlation of parameters in the model to ensure factor validity. Finally, RMSEA (i.e., root mean squared error of approximation) was used to approximate model error. A value of less than 0.05 was used based on established guidelines [20].

\section{Results}

Table 2 illustrates differences between females in the analytic sample and those who did not meet our inclusion criteria. It also provides a summary of the analytic sample's personal characteristics. The analytic sample was more likely than the females omitted from the study to have a regular family physician $(\beta=6.49, \mathrm{p}=0.011)$. This was the only statistically significant difference to the females omitted from our study. However, a Pearson correlation test indicated no relationship ( $\beta=-0.029, \mathrm{p}=0.565)$ between having a family physician and the dependent variable (responsibility to initiate discussion of family health history with a physician). As such, there is no bias from the sample participants being more likely to have a family physician than the females omitted from the study. The analytic sample was also comprised primarily of non-Hispanic whites, 20-24 years old, who mostly came from well educated families.

After evaluating iterations of the model, we determined two factors had a statistically significant relationship to the dependent variable. This resulted in a final model (Figure 1) that best predicted changes in perceived patient-physician responsibility for initiating family health history discussions based on factors concerning perceived importance of heart disease self-risk factors $(\beta=0.21, p=0.005)$ and factors based on cues from friends and acquaintances to obtain family health history $(\beta=-0.17, p=0.022)$. For each unit increase of heart disease self-risk factors, the perceived responsibility for initiating family health history discussions shifted toward the physician. For each unit increase of cues from friends and acquaintances to obtain family health history, the perceived responsibility for initiating family health history discussions shifted toward the patient (i.e., the college student).

The overall model fit statistics from this final model confirmed the importance of these factors' influence on the dependent variable. The CMIN/df was1.481 indicating strong overall model fit to the data set. The measures of parameter correlation and significance were also strong (i.e., TLI $=0.966$ and CFI $=0.984$ ). Finally, the RMSEA of 0.046 indicates a model that adequately minimizes error.

\section{Discussion}

The relationship between heart disease self-risk factors and responsibility for initiating family health history discussions was not expected. Intuitively, we expected that as perception of risk factor importance was increased, the perceived responsibility of discussing family health history would lie with the patient (i.e., the college student) because of their knowledge of the importance of these risk factors. However, further examination of the literature may provide an explanation for this seemingly paradoxical relationship.

\begin{tabular}{|c|c|c|c|c|c|c|}
\hline & & $\begin{array}{c}\text { Analytic Sample (N } \\
=232)\end{array}$ & $\begin{array}{c}\text { Female } \\
\text { Respondents } \\
\text { Not in sample (N } \\
=190)\end{array}$ & $\begin{array}{l}\text { All Female } \\
\text { Respondents } \\
(\mathrm{N}=422)\end{array}$ & $\mathrm{X}^{2}$ & $\mathrm{P}$ \\
\hline Age & \begin{tabular}{r|}
18 \\
19 \\
20 \\
$21-24$ \\
$25+$
\end{tabular} & $\begin{array}{r}22(9.5 \%) \\
43(18.5 \%) \\
68(29.3 \%) \\
89(38.4 \%) \\
10(4.3 \%)\end{array}$ & $\begin{array}{r}15(7.9 \%) \\
32(16.8 \%) \\
67(35.3 \%) \\
64(33.7 \%) \\
12(4.3 \%)\end{array}$ & $\begin{array}{r}37(8.8 \%) \\
75(17.8 \%) \\
135(32.0 \%) \\
153(36.3 \%) \\
22(5.2 \%)\end{array}$ & 6.65 & 0.466 \\
\hline Regular Family Physician & \begin{tabular}{r|} 
Yes \\
No \\
Missing
\end{tabular} & $\begin{array}{r}188(81.0 \%) \\
44(19.0 \%) \\
0(0.0 \%)\end{array}$ & $\begin{array}{r}117(61.6 \%) \\
50(26.3 \%) \\
23(12.1 \%)\end{array}$ & $\begin{array}{r}305(72.3 \%) \\
94(22.3 \%) \\
24(5.4 \%)\end{array}$ & 6.49 & 0.011 \\
\hline Ethnicity & $\begin{array}{r}\text { White } \\
\text { African-American } \\
\text { Asian } \\
\text { Hispanic } \\
\text { American-Indian } \\
\text { Other } \\
\text { Multi-Ethnic }\end{array}$ & \begin{tabular}{r|}
$182(78.4 \%)$ \\
$8(3.4 \%)$ \\
$12(5.2 \%)$ \\
$15(6.5 \%)$ \\
$7(3.0 \%)$ \\
$4(1.7 \%)$ \\
$4(1.7 \%)$
\end{tabular} & \begin{tabular}{r|}
$136(71.6 \%)$ \\
$10(5.3 \%)$ \\
$14(7.4 \%)$ \\
$25(13.2 \%)$ \\
$1(0.5 \%)$ \\
$3(1.6 \%)$ \\
$1(0.5 \%)$
\end{tabular} & \begin{tabular}{r|}
$317(75.4 \%)$ \\
$18(4.3 \%)$ \\
$26(6.2 \%)$ \\
$42(9.5 \%)$ \\
$8(1.9 \%)$ \\
$7(1.7 \%)$ \\
$5(1.2 \%)$
\end{tabular} & 16.35 & 0.129 \\
\hline Education of the Father & $\begin{array}{r}<8^{\text {th }} \text { Grade Education } \\
\text { Some High School } \\
\text { Completed High School } \\
\text { Some College } \\
\text { Completed College } \\
\text { Some Graduate School } \\
\text { Completed Graduate School } \\
\text { Don't know or Not Applicable } \\
\text { Missing }\end{array}$ & \begin{tabular}{r|}
$4(1.7 \%)$ \\
$6(2.6 \%)$ \\
$30(12.9 \%)$ \\
$48(20.6 \%)$ \\
$79(33.9 \%)$ \\
$7(3.0 \%)$ \\
$55(23.6 \%)$ \\
$3(1.3 \%)$ \\
$0(0.0 \%)$
\end{tabular} & \begin{tabular}{r|}
$3(1.6 \%)$ \\
$3(1.6 \%)$ \\
$31(16.3 \%)$ \\
$36(18.9 \%)$ \\
$58(30.5 \%)$ \\
$7(3.7 \%)$ \\
$37(19.5 \%)$ \\
$7(3.7 \%)$ \\
$8(4.2 \%)$
\end{tabular} & \begin{tabular}{r|}
$7(1.7 \%)$ \\
$9(2.1 \%)$ \\
$61(14.5 \%)$ \\
$84(19.9 \%)$ \\
$137(32.5 \%)$ \\
$14(3.3 \%)$ \\
$92(21.8 \%)$ \\
$10(2.4 \%)$ \\
$8(1.9 \%)$
\end{tabular} & 5.25 & 0.629 \\
\hline Education of the Mother & $\begin{array}{r}<8^{\text {th }} \text { Grade Education } \\
\text { Some High School } \\
\text { Completed High School } \\
\text { Some College } \\
\text { Completed College } \\
\text { Some Graduate School } \\
\text { Completed Graduate School } \\
\text { Don't know or Not Applicable } \\
\text { Missing }\end{array}$ & \begin{tabular}{r|}
$3(1.3 \%)$ \\
$8(3.4 \%)$ \\
$28(12.1 \%)$ \\
$62(26.7 \%)$ \\
$85(36.6 \%)$ \\
$10(4.3 \%)$ \\
$36(15.5 \%)$ \\
$0(0.0 \%)$ \\
$0(0.0 \%)$
\end{tabular} & \begin{tabular}{r|}
$2(1.1 \%)$ \\
$3(1.6 \%)$ \\
$36(18.9 \%)$ \\
$53(27.9 \%)$ \\
$56(29.5 \%)$ \\
$5(2.6 \%)$ \\
$23(12.1 \%)$ \\
$4(2.1 \%)$ \\
$8(4.2 \%)$
\end{tabular} & \begin{tabular}{r|}
$5(1.2 \%)$ \\
$11(2.6 \%)$ \\
$64(15.2 \%)$ \\
$115(27.3 \%)$ \\
$141(33.4 \%)$ \\
$15(3.6 \%)$ \\
$59(14.0 \%)$ \\
$4(0.9 \%)$ \\
$8(1.9 \%)$
\end{tabular} & 12.82 & 0.077 \\
\hline
\end{tabular}

Table 2: Personal Characteristic Comparisons between Analytic Sample and Omitted Female Respondents. 


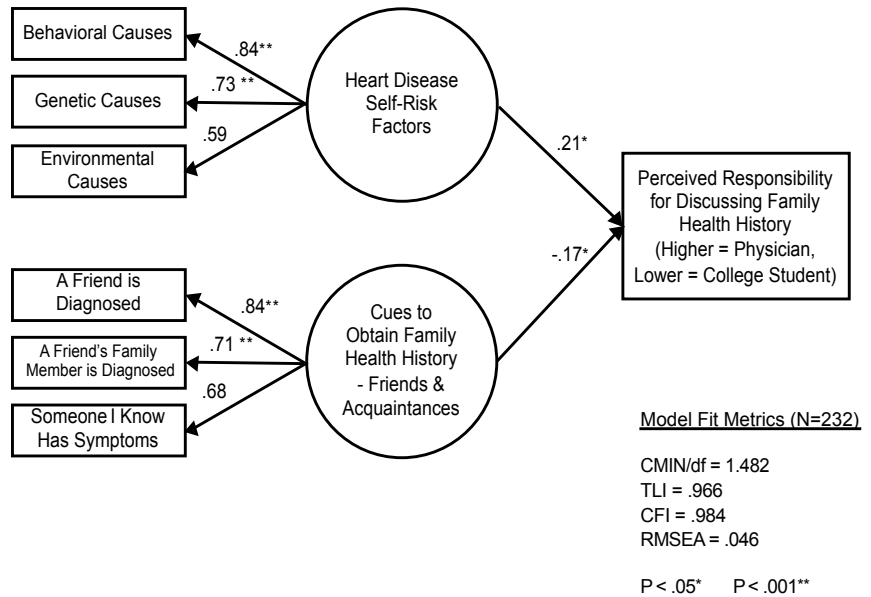

Figure 1: Structural Equation Model of Heart Disease and Family Health History Constructs of College Women with an Association to Individuals with Heart Disease

As demonstrated in Table 1, the most significant component of this factor was self-risk assessment of the behavioral causes of heart disease. Based on studies examining the positive self-risk assessments of children with parents who suffered premature coronary heart disease [25], it is possible these college women viewed their own behaviors as better than those in their family lineage. Hunt et al. [26] found that among 23-year-olds with a perceived family history of heart disease, nearly $50 \%$ reported they were unlikely to get heart disease. This same group believed that if heart disease ran in their family, it was very important for them to exercise [26]. This belief was more pronounced among 23-year-olds in the study than among the 43-year-old and 63-year-old groups, respectively [26]. Believing the risk of heart disease can be controlled with healthier behavioral choices than those engaged in by their relatives may be a strongly held view among younger people and the participants in this study.

It should be noted that genetic causes of heart disease was also closely related to the overall heart disease self-risk factor. If respondent's self-risk assessment of genetic causes of heart disease was noteworthy, it begs the question why these respondents ascribed more responsibility to their physicians to initiate family health history discussions. One possible explanation comes from a study by Hastrup et al. [27] indicating how the accuracy of cardiovascular family history among younger people begins to deteriorate as they move beyond their parent's generation. This could suggest younger people don't know enough about their family health histories to fully appreciate genetic risk factors, even though they recognize their importance. This is similar to the findings of Weiner et al. [28] that examined the beliefs of people with a family history of hypercholesterolemia and coronary heart disease and discovered that genetic factors were considered important, but not absolute.

This study makes a noteworthy finding about the influence of friends and acquaintances in motivating college women to obtain their family health history and take responsibility for initiating family health history discussions with their physician. To our knowledge, this is the first time such a finding has been made among college women.

Montgomery et al. [29] found that among other diseases, women perceive a higher level of risk for heart disease when a friend is diagnosed. This finding was unique to women [29]. It is striking to see the apparent vicarious association played by friends of college women in comparison to family and educational resources. The current generation of young women is likely the most socially connected in history. With a social fabric connected through technological mediums such as the internet and associated social networking applications, it is intuitively realistic to believe friends play a significant role in the lives of college women. Our finding of the enhanced responsibility for discussing family health history given a diagnosed friend or acquaintance may speak to this new era of connectivity between social networks. The instantaneous communication of negative circumstances of one member of the network could produce a "shock" factor among the other network members which induces self-motivation. This is supposition based on the findings of our study, but it does speak to the need for further investigation of the role social networks play in determining how involved college women become in their management of family health history.

\section{Limitations}

There are several strengths of our study. First, we had access to a large and diverse sample. Second, our study is among the first to investigate the issue of responsibility for initiating family health history discussions with physicians among college women, a population becoming more important to the epidemiological issue of heart disease in women [5]. Finally, our study is unique in its inclusion of diverse groups of individuals beyond immediate family members, such as friends and acquaintances. This appears to be of significance in the new age of social networking and its implications for health promotion.

Our study also has limitations. The survey population was from a single college campus which may or may not be representative of the attitudes of college women across the country. Second, our study did not focus on lifestyle behaviors of the respondents (e.g., diet, physical activity and smoking). A better understanding of such behaviors would help validate some of the responses in the survey. Finally, family health history as a concept is one that is not universally defined [30]. Among younger people, it is possible that results were influenced by differing interpretations of the phrase, "family health history."

\section{Conclusion}

As heart disease continues to be a major public health issue among American women there will continue to be opportunities to address prevention topics at earlier stages of life. Our study illustrates that for college women to take more responsibility for obtaining and discussing family health history, educational and clinical efforts must focus on addressing the perception of college women's lifestyle and behavioral choices relative to those in their family history. Also, understanding the unique role of friends in the lives of college women may open an avenue in motivating them to take more responsibility for discussing their family health history with their physician.

\section{References}

1. Centers for Disease Control and Prevention (2010) CDC - DHDSP - Heart Disease Facts.

2. Centers for Disease Control and Prevention (2010) Division for Heart Disease and Stroke Prevention - Women and Heart Disease Fact Sheet.

3. American Cancer Society (2006) Cancer Facts \& Figures.

4. Mosca L, Jones WK, King KB, Ouyang P, Redberg RF, et al. (2000) Awareness perception, and knowledge of heart disease risk and prevention among women in the United States. American Heart Association Women's Heart Disease and Stroke Campaign Task Force. Arch Fam Med 9: 506-515.

5. Ford ES, Capewell S (2007) Coronary heart disease mortality among young 
Citation: Dickerson JB, Smith ML, Sosa E, McKyer ELJ, Ory MG (2012) Perceived Responsibility to Initiate Family Health History Discussions among College Women Associated with Individuals Diagnosed with Heart Disease: Primary Health Care 2:109. doi:10.4172/2167-1079.1000109

adults in the U.S. from 1980 through 2002: concealed leveling of mortality rates. J Am Coll Cardiol 50: 2128-2132.

6. Crouch MA, Gramling R (2005) Family history of coronary heart disease: evidence-based applications. Prim.Care 32: 995-1010.

7. Silberberg JS, Wlodarczyk J, Fryer J, Robertson R, Hensley MJ (1998) Risk associated with various definitions of family history of coronary heart disease. The Newcastle Family History Study II. Am J Epidemiol 147: 1133-1139.

8. Romero DR, McMahan S, Cathorall M (2005) Cardiovascular disease (CVD) risk: should we target college women. Calif J Health Promot 3: 117-129.

9. Patel MJ, de Lemos JA, Philips B, Murphy SA, Vaeth PC, et al. (2007) Implications of family history of myocardial infarction in young women. Am Heart J 154: 454-460.

10. Frich JC, Malterud K, Fugelli $P$ (2006) Women at risk of coronary heart disease experience barriers to diagnosis and treatment: a qualitative interview study. Scand J Prim Health Care 24: 38-43.

11. Smith ML, Sosa ET, Tisone CA, McKyer ELJ (2011) Quality Enhancement Groups: A Qualitative Research Method for Survey Instrument Development. Journal of Health Behavior and Public Health 1: 15-22.

12. StatSoft (2010) Principal Components and Factor Analysis.

13. Hair J, Tatham R, Anderson R, Black W (1998) Multivariate Data Analysis. (5thedn), Prentice Hall, Englewood Cliffs, NJ.

14. Radzius A, Moolchan ET, Henningfield JE, Heishman SJ, Gallo JJ (2001) A factor analysis of the fagerstrom tolerance questionnaire. Addict Behav 26: 303-310

15. McLaughlin FE, Marascuilo LA (1990) Advanced nursing and health care research: Quantification approaches. WB Saunders \& Co, Philadelphia, PA.

16. Frank-Stromborg M, Olsen SJ (2004) Instruments for clinical health-care research. Jones \& Bartlett, Sudbury, MA.

17. IBM (2010) SPSS Amos.
18. IBM (2010) SPSS Statistics.

19. Tanaka JS (1987) "How Big Is Big Enough?": Sample Size and Goodness of Fit in Structural Equation Models with Latent Variables. Child Dev 58: 134-146.

20. Dion PA (2008) Interpreting Structural Equation Modeling Results: A Reply to Martin and Cullen. J Bus Ethics 83: 365-368.

21. Bentler PM, Bonett DG (1980) Significance tests and goodness of fit in the analysis of covariance structures. Psychol Bull 88: 588-606.

22. Bentler PM (1990) Comparative fit indexes in structural models. Psychol Bull 107: $238-246$.

23. Browne MW (1992) Alternative Ways of Assessing Model Fit. Sociologica Methods and Research 21: 230-258.

24. Marsh HW, Hocevar D (1985) Application of confirmatory factor analysis to the study of self-concept: first- and higher order factor models and their invariance across groups. Psychol Bull 97: 562-582.

25. Allen JK, Blumenthal RS (1998) Risk factors in the offspring of women with premature coronary heart disease. Am Heart J 135: 428-434.

26. Hunt K, Davison C, Emslie C, Ford G (2000) Are perceptions of a family history of heart disease related to health-related attitudes and behaviour. Health Educ Res 15: 131-143.

27. Hastrup JL, Hotchkiss AP, Johnson CA (1985) Accuracy of knowledge of family history of cardiovascular disorders. Health Psychol 4: 291-306.

28. Weiner K, Durrington PN (2008) Patients' Understandings and Experiences of Familial Hypercholesterolemia. Community Genet 11: 273-282.

29. Montgomery G, Erblich J, DiLorenzo T, Bovbjerg DH (2003) Family and friends with disease: their impact on perceived risk. Prev Med 37: 242-249.

30. Parmar MS (2003) Family history of coronary artery disease-need to focus on proper definition. Eur Heart J 24: 2073. 